\title{
Exclusão do imposto sobre operações de circulação de mercadorias-ICM da base de cálculo da contribuição para o financiamento social-COFINS ${ }^{1}$
}

\author{
Wylton Carlos Gaion ${ }^{2}$ \\ Profa. Dra. Marlene Kempfer Bassoli ${ }^{3}$
}

\begin{abstract}
Resumo
0 presente artigo tem o intuito de analisar a questão da inclusão do ICM na base de cálculo da COFINS, um tema de grande relevância no atual cenário jurídico, ante 0 julgamento no Supremo Tribunal Federal do Recurso Extraordinário no 240.785-M G e Ação Direta de Constitucionalidade no 18, de iniciativa da Presidência da República, através da Advocacia Geral da União. Do exposto pode-se chegar aos resultados: a) percebeu-se que 0 imposto sobre circulação de mercadorias não se subsume nos termos "faturamento" e "receita", ambos base de cálculo da contribuição para financiamento da seguridade social-COFINS; b) a inclusão do ICM na base de cálculo da COFINS não respeita a regra-matriz constitucional da COFINS. Conclui que a inclusão do Imposto sobre circulação de mercadoria-ICM na base de cálculo da contribuição para financiamento da seguridade social-COFINS está em confronto direto com a constituição, devendo o Supremo Tribunal Federal ao analisar a constitucionalidade de tal inclusão, considerar elementos jurídicos e julgar pela inconstitucionalidade de tal procedimento e não deixar-se levar por conceito políticos e econômicos e colocar em "xeque" a supremacia constitucional.
\end{abstract}

Palavras-Chave: Exclusão; ICM; Base de Cálculo; COFINS.

\section{Introdução}

Muita discussão existe sobre esse tema, havendo posicionamentos favoráveis à inclusão do imposto sobre a operação de circulação de mercadorias na base de cálculo da contribuição para financiamento da seguridade social, pelo fato de acreditarem que o valor do ICM compõe o preço da mercadoria, e contrários a essa inclusão, pois argumentam que esse valor não compõe o preço da mercadoria, mas o valor da operação do próprio ICM , e por essa quantia não corresponder ao conceito de faturamento, nem de receita.

1 Este ensaio teve por referência Trabalho de Conclusão de Curso apresentado ao Curso de Direito da Universidade Estadual de Londrina, de autoria do primeiro sob a orientação da segunda.

2 Aluno do 50 ano de Direito da Universidade Estadual de Londrina.

3 Doutora em Direito do Estado - Direito Tributário pela PUC-SP. Professora de Direito Tributário na graduação do Curso de Direito da Universidade Estadual de Londrina e PUC-Londrina, dos programas de Mestrado em Direito da Universidade Estadual de Londrina e da Universidade de Marília. 
Com relação à possibilidade da exclusão do ICM da base de cálculo da COFINS, será abordada a necessidade dessa exclusão ocorrer, uma vez que o valor da operação do ICM , em especial o seu valor incluso na sua própria base de cálculo, é técnica de apuração da quantia a ser paga apenas para esse imposto, mas não integrante do preço da mercadoria, que corresponde ao valor da operação da COFINS. Na seqüência será abordada a necessidade da exclusão ocorrer uma vez que não há correspondência entre esse imposto e os conceitos de faturamento e receita, ambos base de cálculo da COFINS. Após, será exposto o posicionamento do Superior Tribunal de Justiça, que já pacificou entendimento pela inclusão do imposto sobre circulação de mercadorias da base de cálculo da COFINS, inclusive editou a Súmula 94 permitindo a inclusão do ICM na base de cálculo da COFINS. Será explanada a atual discussão no Supremo Tribunal Federal, em especial o recurso extraordinário no 240.785-M G que tendia a declarar inconstitucional a inclusão do ICM na base de cálculo da COFINS, no qual o entendimento majoritário do pleno era pela inconstitucionalidade da inclusão no recurso extraordinário, até então seis votos favoráveis e um contra referente à exclusão do ICM , e a ação direta de constitucionalidade número 18, proposta pelo Advogado-Geral da União, em nome do Presidente da República.

\section{Pontos relevantes e a problemática da inclusão}

O imposto sobre a operação de circulação de mercadorias e mesmo sobre a prestação de serviço de transporte interestadual e intermunicipal e de comunicação são tributos indiretos. Significa dizer que o ônus tributário não é suportado pela pessoa que realiza a operação mercantil, mas pelo consumidor.

Na sua base de cálculo, segundo a lei complementar no 87/96 (Kandir), em seu

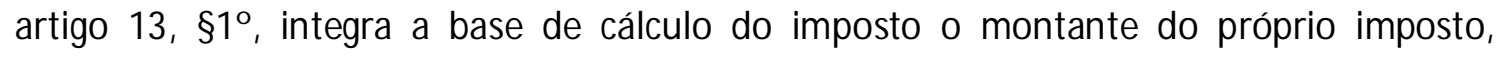
constituindo o respectivo destaque mera indicação para fins de controle.

Esse mecanismo, denominado de repercussão econômica, é conhecido como "cálculo por dentro" e tem como objetivo estabelecer que a quantia de ICM já esteja inclusa quando da venda da mercadoria para o consumidor. Por exemplo, se a mercadoria for vendida por $\mathrm{R} \$ 100,00$ (cem reais), e uma alíquota de $18 \%$, o valor do tributo a título de ICM será de $R \$ 21,95$ (vinte e um reais e noventa e cinco centavos), já incluso naquele primeiro valor da mercadoria. Por isso denomina-se de "cálculo por dentro", por que o valor já estará 


\section{Exclusão do imposto sobre operações de circulação de mercadorias-ICM da base de cálculo da contribuição para o financiamento social-COFINS}

incluso no valor da mercadoria repassada para o consumidor (CARRAZA, 2007, p. 282). No exemplo, se o cálculo fosse "por fora", como no imposto sobre produtos industrializados, 0 valor em vez de ser $\mathrm{R} \$ 100,00$ (cem reais), seria $\mathrm{R} \$ 121,95$ (cento e vinte e um reais e noventa e cinco centavos).

Carrazza (2007, p. 282) estabelece a fórmula para se chegar a tal resultado, considerando a alíquota de 18\%, e o valor da mercadoria em $\mathrm{R} \$ 100,00$ (cem reais), como sendo:

ICM S=base de cálculo. 18/(base de cálculo - 18)

ICM S=100.18/100-18;

ICM S=1800/82

ICM S=21,95

Por meio desse cálculo, o valor do ICM compõe a base de cálculo do próprio ICM .

Além da permissão do artigo $13, \S 10$, I, da Lei 87/96, há a permissão constitucional no artigo 155, 2ํ, XII, i, Constituição Federal para se "fixar a base de cálculo, de modo que 0 montante do imposto a integre [...]".

Como conseqüência dessa base de cálculo "por dentro", ou fenômeno da repercussão econômica, o ICM compõe o valor da operação. Mas, como é repassado para 0 consumidor, ele acaba compreendendo o preço da mercadoria, devido ao repasse. Comercialmente o preço da mercadoria compõe o valor dos custos, a margem de lucro da empresa, e o próprio ICM. Frise-se que esse compõe na verdade o valor da operação, mas devido ao repasse pelo empresário, "compõe" o preço da mercadoria.

Pelo fato do ICM ser um tributo indireto e do ônus fiscal que possuem as empresas ao receberem o preço da mercadoria, tirarão a quantia correspondente ao ICM, que já estava embutido no preço e repassarão à fazenda estadual. No exemplo, tirarão dos R\$ 100,00 (cem reais), do valor da mercadoria, a quantia correspondente do tributo, no caso de $R \$ 21,95$ (vinte e um reais e noventa e cinco centavos) e repassarão ao fisco estadual.

A confusão está em que a Receita Federal considera o ICM repassado no preço da mercadoria, não como simples ingresso, mas como faturamento, sem retirar a parcela correspondente a seu valor, que na verdade não é faturamento, afinal, a empresa recebe esse tributo para posterior repasse para a Receita Estadual. Na verdade constitui um ônus fiscal. Os órgãos competentes para arrecadar a COFINS confundem o preço da mercadoria e 
valor da operação, acreditando que o ICM na sua própria base de cálculo seja componente do preço da mercadoria, em vez de fazer parte do valor da operação. Este último entendimento é o correto, como será analisado no próximo item.

Eis a problemática: a União Federal considera legítima a inclusão do ICM na base de cálculo da COFINS. Os empresários contribuintes consideram inconstitucional tal prática, pois viola a regra-matriz constitucional da COFINS, em especial, a sua base de cálculo, já que o conceito de faturamento e receita não comporta o valor do ICM.

\section{Da exclusão do ICM da base de cálculo da cofins por não corresponder ao seu valor da operação}

Basicamente, os argumentos para a exclusão do ICM da base de cálculo da COFINS são dois, mas suficientes para que ela ocorra:

a) o ICM na sua própria base de cálculo é valor da operação e não preço da mercadoria, aplicando-se apenas para a apuração dele mesmo e não de outro produto, nem se aplicando em outro valor da operação, como na COFINS; e

b) a Constituição estabelece como base de cálculo da COFINS o faturamento ou a receita e o ICM não é faturamento, nem tampouco receita.

Trata-se agora da não configuração do ICM na base de cálculo da COFINS, por não se amoldar ao valor da operação deste, para na seqüência abordar sobre a não configuração desse imposto com o conceito de faturamento e receita.

O ICM calculado em sua própria base de cálculo não compõe propriamente dito, 0 preço da mercadoria, nem tampouco o valor da operação da COFINS, mas compõe apenas o valor da operação do próprio ICM. 0 fisco federal considera o preço da mercadoria como abrangido por faturamento, e que o valor do ICM calculado na sua própria base de cálculo compõe o preço e não o valor da operação a ser pago a título de ICM, representando mero ingresso, para posterior repasse para o fisco estadual.

Para demonstrar esses argumentos, faz mister esclarecer a diferença entre preço da mercadoria, valor da operação do ICM , e valor da operação da COFINS.

Preço do bem, da mercadoria ou do serviço prestado, não se confunde com o valor da operação,tendo conceitos diferentes, bem como natureza, finalidade e alcances próprios. 


\section{Exclusão do imposto sobre operações de circulação de mercadorias-ICM da base de cálculo da contribuição para o financiamento social-COFINS}

No próprio artigo 13, da lei complementar n- 87/96 percebe-se que valor da operação e preço do bem são diversos:

Art. 13. A base de cálculo do imposto é:

I - na saída de mercadoria prevista nos incisos I, III e IV do art. 12, 0 valor da operação;

II - na hipótese do inciso II do art. 12, o valor da operação, compreendendo mercadoria e serviço;

III - na prestação de serviço de transporte interestadual e intermunicipal e de comunicação, o preço do serviço;

$\S 1_{\underline{l}}$ Integra a base de cálculo do imposto, inclusive na hipótese do inciso $\mathrm{V}$ do caput deste artigo:

I - o montante do próprio imposto, constituindo o respectivo destaque mera indicação para fins de controle;

II - o valor correspondente a:

a) seguros, juros e demais importâncias pagas, recebidas ou debitadas, bem como descontos concedidos sob condição;

b) frete, caso o transporte seja efetuado pelo próprio remetente ou por sua conta e ordem e seja cobrado em separado.

Pelo exposto percebe-se que o ordenamento trata de maneira diversa o preço da mercadoria de valor da operação. Devem-se buscar as diferenças entre "preço do bem" e "valor da operação".

Aires Barreto, na obra "Base de cálculo, alíquota e princípios constitucionais", ao tratar do valor da operação e preço do bem, expressa:

Geralmente, preço e custo são tidos como equivalentes. Mas, em regra, o custo significa o preço de produção ou o valor monetário por que a coisa foi adquirida.

Possui, assim, sentido mais estrito, porquanto preço entende-se toda avaliação monetária ou todo valor pecuniário, atribuído à coisa, sem atenção ao custo originário ou preço de custo. (FORTES, 2008)

Maria Helena Diniz (apud FORTES, 2008), no mesmo sentido, conceitua preço da mercadoria como:

Soma em dinheiro que o comprador paga ao vendedor em troca da coisa adquirida. [...] Além da pecuniaridade, o preço deverá ter: a) seriedade, indicando firme objetivo de se constituir numa contraprestação relativamente ao dever do alienante de entregar a coisa vendida, de modo que não denuncie qualquer simulação absoluta ou relativa; não pode ser fictício nem irrisório; b) certeza, pois deve ser certo ou determinado para que o comprador possa efetuar o pagamento devidamente. 0 preço, em regra, é fixado pelos contratantes no ato de contratar. 
O custo significa o preço de produção ou o valor monetário por que a coisa foi adquirida, possuindo sentido mais estrito, enquanto por preço entende-se toda avaliação monetária ou todo valor pecuniário, atribuído à coisa, não se considerando o custo originário ou preço de custo. Representa a soma em dinheiro, em que se determina o valor da coisa para que sirva de base à operação de que será objeto. Nas vendas, o preço é a quantia ou a soma pecuniária a ser paga pelo comprador, um valor expresso em dinheiro, e relativamente às mercadorias, entende-se em sentido equivalente a cotação.

0 preço consiste em um parâmetro pecuniário para fins de negociação de bens, que por se tratar de parâmetro pode ou não corresponder ao respectivo custo. Frise-se que serão as partes que estabelecerão o preço à coisa, tratando-se, de expressão pecuniária voltada ao aspecto pragmático da contratação.

O valor da operação, em contrapartida, é critério jurídico. É o ordenamento jurídico que atribui à negociação efeito diverso que a mera troca de bens, como ocorre, por exemplo, com a tributação. E

as partes, ao efetuar operações de circulação de mercadoria ou com produtos industrializados, repercutem no campo tributário, o qual elege uma grandeza econômica para a incidência dos respectivos tributos, grandeza esta representada pelo valor, consubstanciado pelo preço do produto acrescido das parcelas legalmente determinadas, dentro dos parâmetros da competência tributária. [...] inserido no contexto jurídico, "valor" se referirá a uma grandeza econômica legalmente qualificada, composto de parcelas monetárias certas e determinadas. (FORTES, 2008)

O preço é parâmetro econômico para fins de negociação, sendo, inclusive estabelecido pelas partes, dotado de caráter empírico-pragmático; enquanto valor da operação é parâmetro jurídico, para fins de tributação, no caso em tela, "[...] do que é possível abstrair 'valor da operação' para fins de IPI e 'valor da operação' para fins de ICMS não se confundem." (FORTES, 2008)

Considerando que o valor da operação é parâmetro jurídico, no caso com a finalidade de apuração do tributo, é possível perceber que:

a) o valor da operação do ICM é diverso do valor da operação da COFINS;

b) 0 valor da operação da COFINS diz respeito à venda de mercadorias, de mercadorias e serviços e de serviços de qualquer natureza, enquanto o valor da 


\section{Exclusão do imposto sobre operações de circulação de mercadorias-ICM da base de cálculo da contribuição para o financiamento social-COFINS}

operação do ICM tem relação com a circulação de mercadorias, sendo, portanto, diferentes;

c) no valor da operação do ICM , no art. 13, §1ํㅡ, I, da Lei Complementar no 87/96, há expressa previsão para que o ICM possa ser compreendido em sua própria base de cálculo. Seu "valor da operação" é o preço da mercadoria estabelecido entre as partes, acrescido do montante do próprio ICM, dos seguros, dos juros, das demais importâncias pagas, recebidas ou debitadas, descontos concedidos sob a condição e frete. Nesse último caso, o fenômeno da repercussão econômica é um mecanismo ligado unicamente à apuração do ICM ;

d) o valor da operação da COFINS basicamente é composto pelo preço da mercadoria.

Se o ICM tem valor de operação diverso, haja vista que na legislação da COFINS não tem essa previsão do ICM fazer parte do valor da operação daquela contribuição, bem como possuem materialidades diversas, não há nenhuma possibilidade de se admitir a inclusão do ICM na base de cálculo da COFINS, pois a permissão estabelecida na lei "Kandir" é parâmetro de apuração única e exclusiva do ICM e não da COFINS, inexistindo motivos para se permitir que um valor que sirva de parâmetro para apuração da quantia devida a título de ICM sirva na base de cálculo de uma contribuição que tem como valor de operação o preço da venda.

Pelo fato de terem "valor de operação" diferente, conseqüentemente tanto o ICM , quanto à COFINS terão regimes jurídicos diferentes, aplicando normas jurídicas correspondente a cada regime. Se no regime do ICM permite a inclusão do seu próprio valor em sua base de cálculo, não deverá aplicar em outro tributo de regime jurídico diverso. A lei que prevê essa possibilidade do ICM incluso em sua própria base de cálculo é parâmetro para se apurar a quantia de ICM. Essa permissão é para ele apenas, não abrindo possibilidades para nenhuma outra.

Frise-se que como o valor da operação do ICM é composto do valor do próprio ICM, que se aplica somente a ele próprio, e considerando a base de cálculo da COFINS o faturamento, que corresponde à receita bruta da venda de mercadorias, e esta venda corresponde ao preço da mercadoria, seria correto retirar a quantia correspondente ao valor do ICM do preço da mercadoria, que estava embutido, "por dentro", haja vista que esse 
imposto não se amolda à base de cálculo da COFINS, seja sob o prisma do termo faturamento, seja pela ótica da receita, apenas ingressando, transitoriamente, no caixa da empresa.

É possível entender que sob a ótica do valor da operação da COFINS, o "valor da operação", que é o valor da venda de mercadorias e de mercadorias e serviços, consubstanciada no faturamento mensal, ou como estabelece Luis Fernando de Souza, realizar operações jurídicas de vendas (NEVES, 1997, p. 98), é diverso do valor da operação do ICM, que possui "valor da operação" composto do preço da mercadoria, estabelecido entre as partes, acrescido, entre outros, do montante do próprio ICM. Estabelecendo esse paralelo, fica visível a distinção de que o "valor da operação" da COFINS é o preço da mercadoria, preço da venda, enquanto o "valor da operação" do ICM abrange o preço da mercadoria e o do próprio ICM, que se aplica somente no caso de apuração do valor do próprio ICM, devendo ser excluído tal valor da base de cálculo da COFINS.

O ICM integra o "valor da operação" dele mesmo, por força do estabelecido no artigo 13 da lei no 87/96, mas não integra o valor da mercadoria. Não é lícito considerar 0 valor da operação do ICM , que considera o valor do próprio imposto em sua base de cálculo, para se apurar outro tributo, sem permissão constitucional ou legal, inserindo-o em outra base de cálculo, como o da COFINS. Se ambas possuem regimes jurídicos distintos, não há que permitir que seja incluso na base de cálculo da referida contribuição à seguridade social um parâmetro jurídico de um imposto, "valor da operação" do ICM, haja vista que não tem previsão legal, nem constitucional para que tal inclusão ocorra. A Constituição Federal, no artigo 155, §2으, XII, alínea i, e a Lei Complementar no 87/96, artigo 13, §1oㅡ, I, permitem a inclusão do ICM na sua própria base de cálculo, que abrange tanto o valor do ICM , como 0 preço da mercadoria, mas não há nenhuma outra permissão para a inclusão desse valor na base de cálculo da contribuição para o financiamento da seguridade social. 0 "valor da operação" desse imposto só se aplica a ele. 0 "valor da operação" da COFINS só a ela se aplica. 


\section{Exclusão do imposto sobre operações de circulação de mercadorias-ICM da base de cálculo da contribuição para o financiamento social-COFINS}

\section{Exclusão do ICM da base de cálculo da cofins por não corresponder ao conceito de faturamento e receita}

O STF chamado para se manifestar sobre a constitucionalidade da Lei Completar no 70/91, através da $A D C$ № 1, entendeu que o faturamento, para efeitos fiscais, sempre fora considerado como a receita proveniente das vendas de mercadorias e serviços, coincidindo com o de receita bruta, proveniente de vendas de mercadoria, de mercadorias e serviços e serviços de qualquer natureza (art. $2^{\circ}, \mathrm{LC} \mathrm{n} 0 \mathrm{0} 70 / 91$ ).

Contudo, devido ao fenômeno da repercussão econômica, ou a base de cálculo "por dentro", o ICM incide sobre o valor da operação do próprio ICM, integrando sua base de cálculo. Como conseqüência, quando o consumidor paga o preço da mercadoria, já paga o tributo incluso.

Esse valor de ICM entra no caixa da empresa, juntamente com o preço da mercadoria. Lembre-se que o ICM não compõe o preço da mercadoria, mas apenas o valor da operação do ICM , por força constitucional e de acordo com a lei complementar no 87/96. Ao ingressar no caixa da empresa, esse valor não ficará para a empresa, não fará parte do seu patrimônio, mas será repassado para a Secretaria da Receita Estadual, afinal constitui receita dela, credora do crédito.

Configura-se como mero ingresso no caixa da empresa para posterior repasse para o fisco estadual. Este sim possui o crédito do ICM como receita.

Trata-se de um ônus fiscal, que a empresa tem que cumprir.

$\mathrm{Na}$ verdade, o ICM integra o valor da operação para fins de apuração da quantia de ICM devido, que é repassado para o consumidor. Não integra o preço da mercadoria. E como a COFINS incide sobre o preço da mercadoria, não deve incidir sobre o ICM .

0 correto seria considerar o faturamento descontado o valor de ICM repassado para a Fazenda Estadual.

Note-se que o conceito de faturamento tem íntima relação com receita bruta da venda de mercadorias, de mercadorias e serviços, e de serviço de qualquer natureza. $\mathrm{Ou}$ seja, faturamento é uma espécie de receita: receita bruta.

Como receita bruta que é, deverá respeitar o estabelecido sobre as receitas, como estabelece Aires Barreto, no artigo "ISS - Atividade-meio e Serviços- fim": "as receitas são 
entradas que modificam o patrimônio da empresa, incrementando-o." (PAULSEN, 2007, p. 471.)

Ao contrário, ingresso é termo mais abrangente, que engloba as receitas e as somas pertencentes a terceiros, que integram o patrimônio de outrem, para posterior entrega.

Neste diapasão, o que ocorre com o ICM tem caráter de ingresso e não de receita, haja vista que essa quantia pertence ao fisco (terceiro) e lhe é repassada posteriormente, devido ao fenômeno da repercussão econômica, que estabelece um ônus ao empresário para repassar a quantia composta em sua base de cálculo à Fazenda Estadual. Um fenômeno de ordem econômica não tem o condão de transformar o conceito faturamento ou receita tributável, que são conceitos jurídicos.

Os requisitos de uma receita tributável são: ocorrer ingresso de recursos financeiros no patrimônio da pessoa jurídica; que este ingresso esteja vinculado ao exercício de atividade empresarial; que represente uma contraprestação em negócio jurídico que envolva a venda de mercadorias ou prestação de serviços, ou pela cessão onerosa de bens e direitos e remuneração de investimentos; que esse ingresso tenha caráter definitivo, e que haja uma mensuração instantânea e isolada em cada evento, abstraindo-se dos custos e de periodicidade para sua apuração. Esse valor de ICM não respeita os requisitos, pois apenas ingressa no caixa da empresa, sem ter caráter de recurso financeiro no patrimônio da empresa, nem tem caráter definitivo.

Ives Gandra da Silva M artins estabelece que só pode ser considerado como receita 0 ingresso de recursos que passe a fazer parte do patrimônio do contribuinte. 0 simples ingresso não a transforma em receita (apud PAULSEN, 2007, p. 470).

Continua a explanar que o simples ingresso de valores na contabilidade da empresa não é fator que demonstre capacidade contributiva, limite imposto a todos os tributos, inclusive as contribuições (apud PAULSEN, 2007, p. 470). Não se olvide que o conceito de receita, para fins tributários, é jurídico, substancial e não contábil. 0 registro contábil, como o nome diz, não cria, apenas registra.

José Antônio Minatel, na obra "Conteúdo do Conceito de Receita e Regime Jurídico para sua Tributação", em sintonia com o exposto, afirma que para um ingresso ter natureza de receita deverá ser oriundo de atividade empresarial e ter caráter de definitividade (M INATEL, 2005, p. 254). 


\section{Exclusão do imposto sobre operações de circulação de mercadorias-ICM da base de cálculo da contribuição para o financiamento social-COFINS}

O ICM não configura receita, tributável, pois será repassado para o fisco, não tendo caráter definitivo. Configura apenas ingresso, passando pelo seu caixa transitoriamente, para posterior entrega aos cofres públicos.

Nesse ponto, a inclusão do ICM na base de cálculo da COFINS é inconstitucional por violar a base de cálculo estabelecida no artigo 195, I, Constituição Federal, redação original, anterior à Emenda no 20/98; e mesmo após a reforma, pois não configura faturamento, nem receita, haja vista que o ICM não tem a característica de modificar o patrimônio da empresa, positivamente, incrementando-o, o que é característica da receita, nem ter caráter definitivo.

Outra característica da receita, entendida tanto o faturamento, espécie de receita, quanto na receita enquanto gênero, é que ela deve advir de realidade dotada de conteúdo econômico, possibilitando dela extrair uma parcela de riqueza, ou capacidade contributiva, que possibilite ser solidário na manutenção e custeio das atividades do Estado, respeitando os direitos fundamentais da liberdade e propriedade (M INATEL, 2005, p. 253). Ou seja, não é qualquer receita que deve ser tributada, mas apenas as receitas tributáveis, dotada de conteúdo econômico.

O conteúdo da receita, pressuposto pelo constituinte tem na sua essência a diretriz da capacidade contributiva, necessariamente exteriorizada pela disponibilidade de ingresso financeiro proveniente de operações praticadas no exercício da atividade empresarial, como as vendas de mercadorias ou serviços.

Se por um lado, é facilmente perceptível que a admissão de venda de mercadorias e serviços na base de cálculo da COFINS respeita a capacidade contributiva, pois retira parcela de riqueza de uma realidade dotada de conteúdo econômico, a atividade empresarial; por outro, o ICM incluso na operação mercantil, repassado para o consumidor, viola a capacidade contributiva, pois a parcela de riqueza reside na venda de mercadorias e serviços durante atividade empresarial, mas não do ICM que, apesar de ingressar no caixa da empresa, é repassado para a receita estadual, configurando um simples ingresso e um ônus fiscal que o empresário-contribuinte tem que suportar, e em dobro: um pelo dever de repassar para o Estado ou Distrito Federal o valor do ICM , e outro, por ver esse valor incluso, indevidamente, na base de cálculo da COFINS. 
Destarte, é inadmissível a inclusão do ICM na base de cálculo da COFINS, pois esse valor não corresponde ao valor de faturamento, nem de receita e não respeita a capacidade contributiva, exigência para a configuração de receita tributável.

\title{
Posicionamento do Superior Tribunal de Justiça-STJ
}

O posicionamento do Superior Tribunal de Justiça, já se encontrava pacificado a respeito da admissibilidade da inclusão do ICM na base de cálculo da COFINS e do PIS, editando inclusive duas súmulas, as de números 68 e 94, que estabelecem, respectivamente: "A parcela relativa ao ICM inclui-se na base de cálculo da PIS." e "A parcela relativa ao ICMS inclui-se na base de cálculo do FINSOCIAL."

Quanto ao entendimento pacífico do STJ, alguns julgados a título exemplificativo ajudam a aclarar a afirmação acima feita:

\author{
Ementa: \\ PROCESSUAL CIVIL E TRIBUTÁRIO. AGRAVO REGIMENTAL. COFINS. BASE DE \\ CÁLCULO. INCLUSÃO DO ICMS. SÚMULAS №S 68 E 94, DO ST]. \\ 1. Agravo regimental contra decisão que desproveu agravo de \\ instrumento. \\ 2. 0 acórdão a quo, com base nas Súmulas no̊ 68 e 94 do STJ, \\ asseverou estar pacificado o entendimento de que a parcela relativa \\ ao ICMS se inclui na base de cálculo do PIS e da COFINS. \\ 3. Pacífico o entendimento nesta Corte de que a parcela relativa ao \\ ICM S inclui-se na base de cálculo do FINSOCIAL (e, conseqüentemente, \\ da COFINS, tributo da mesma espécie) e também do PIS. Súmulas nํs 68 \\ e 94/ST], respectivamente: "a parcela relativa ao ICM inclui-se na \\ base de cálculo do PIS" e "a parcela relativa ao ICM S inclui-se na \\ base de cálculo do Finsocial." \\ 4. Agravo regimental não provido.

\section{Ementa:} \\ TRIBUTÁRIO - PISE COFINS: INCIDÊNCIA - INCLUSÃO NO ICMS \\ NA BASE DE CÁLCULO. \\ 1. O PIS e a COFINS incidem sobre o resultado da atividade econômica \\ das empresas (faturamento), sem possibilidade de reduções ou deduções. \\ 2. Ausente dispositivo legal, não se pode deduzir da base de cálculo 0 \\ ICMS. \\ 3. Recurso especial improvido." (REsp no 501626/RS, 2a Turma, DJ de \\ 15/09/2003, Rela M in ${ }^{a}$ ELIANA CALM ON)
}

Os julgados do STJ são no sentido da possibilidade da inclusão do ICM na base de cálculo da COFINS. 


\title{
Exclusão do imposto sobre operações de circulação de mercadorias-ICM da base de cálculo da contribuição para o financiamento social-COFINS
}

Basicamente alegam que tudo que ingressa na empresa, a título de preço de mercadoria é faturamento, como estabelecido no recurso especial abaixo:

\author{
Ementa:"TRIBUTÁRIO. COFINS. BASE DE CÁLCULO. ICMS. \\ - Tudo quanto entra na empresa a título de preço pela venda de \\ mercadorias é receita dela, não tendo qual quer relevância, em termos \\ jurídicos, a parte que vai ser destinada ao pagamento de tributos. \\ - Conseqüentemente, os valores devidos à conta do ICMS integram a base \\ de cálculo da Contribuição para Financiamento da Seguridade Social. \\ - Recurso especial não conhecido." (REsp no 152736/SP, 2a Turma, DJ de \\ 16/02/1998, Rel. Min. ARI PARGENDLER).
}

No STJ já se tem o posicionamento a respeito da exclusão do ICM, da base de cálculo da COFINS: são contrários, argumentando que o ICM compõe o preço da mercadoria, e tudo quanto entra na empresa a título de preço pela venda de mercadorias é receita dela. Esse argumento não prospera.

Como oportunamente demonstrado nos itens 3 e 4, embora o ICM seja um tributo indireto, repassado o valor do tributo para o consumidor, a sua "base de cálculo por dentro" é parâmetro para se apurar o "valor da operação" do ICM e não o "valor da operação" da COFINS, que são diversos. Naquela, basicamente o valor da operação é preço da mercadoria mais o valor do ICM , enquanto nesta contribuição para financiamento da seguridade social o valor da operação basicamente é o valor da mercadoria vendida, ou o preço.

Destarte, é equivocado o entendimento do Superior Tribunal de Justiça.

\section{"Posicionamento" do Supremo Tribunal Federal}

O Supremo ainda não se posicionou a respeito da possibilidade da inclusão do ICM da base de cálculo da COFINS.

No Supremo Tribunal Federal, duas ações movimentam e geram bastante discussão: é o recurso extraordinário n² 240.785-M G, relator M inistro Marco Aurélio, e a Ação Direta de Inconstitucionalidade no 18, relator Ministro Menezes Direito.

\section{Recurso extraordinário ํㅜ 240.785-M G}

Esse recurso é anterior à Emenda nํ20/98, e se arrasta há mais de onze anos. Foi apresentada pela empresa "Auto Americano S/A Distribuidor de Peças", inconformada com 
a decisão do Tribunal Regional Federal da 3a Região, ao entender que a questão da constitucionalidade da lei no 70/91 já havia sido decidida na ADIN no 1-1 DF, inclusive a questão da inclusão do ICM na base de cálculo da COFINS.

A defesa da empresa alega a inconstitucionalidade do parágrafo único, artigo 2ํㅡ, da lei complementar no 70/91, pois contraria a redação original do artigo 195, I, da Constituição, que previa apenas faturamento, não prevendo a exclusão do ICM da base de cálculo da COFINS. Embora a ADC no1-1-Distrito Federal, em 1993, julgou constitucional a referida lei, não teria apreciado a constitucionalidade do parágrafo único, do artigo 2ํㅡ, mas apenas os artigos: 1ㅇ, 2ㅇ, 9, 10 e 13 da referida lei.

Nesse recurso, julgado pelo pleno, encontrava-se com seis votos favoráveis à tese da exclusão e apenas um voto favorável à inclusão. Os ministros Marco Aurélio, relator, e os ministros Ricardo Lewandowski, Carlos Britto, César Peluso, Sepúlveda Pertence e Cármen Lúcia votaram pela inconstitucionalidade da inclusão do imposto sobre operação de circulação de mercadorias, prestação de serviços de transporte interestadual e intermunicipal e de comunicação da base de cálculo da COFINS.

0 ministro Eros Grau entendeu que é constitucional, pois estaria em sintonia com o conceito de faturamento.

Um dos pontos que se destacou do voto do relator foi a análise da questão da interpretação de norma estritamente legal. Afirmou o M inistro Marco Aurélio que não se trata de interpretação de norma infraconstitucional, em nível legal, mas refere-se à violação da própria regra-matriz constitucional. E afirmou que o que se deve analisar é se a conclusão a que chegou a Corte de origem, refutando a defesa sobre a inconstitucionalidade de ter-se a incidência do tributo sobre o ICMS, incluindo este no que se entende como faturamento, conflita, ou não, com o dispositivo constitucional.

Estabelece que as expressões utilizadas no inciso I do artigo 195 da Constituição Federal devem ser consideradas no sentido técnico consagrado pela doutrina e jurisprudência. Relembrou o posicionamento do Supremo a respeito da possibilidade de incidência da contribuição, na redação primitiva da Carta, sobre o que pago àqueles que não mantinham vínculo empregatício com a empresa:

Por isso mesmo, esta Corte glosou a possibilidade de incidência da contribuição, na redação primitiva da Carta, sobre o que pago àqueles que não mantinham vínculo 


\section{Exclusão do imposto sobre operações de circulação de mercadorias-ICM da base de cálculo da contribuição para o financiamento social-COFINS}

empregatício com a empresa, emprestando, assim, ao vocábulo "salários", o sentido técnico-jurídico, ou seja, de remuneração feita com base no contrato de trabalho - Recurso Extraordinário № 128.519-2/DF. Jamais imaginou-se ter a referência à folha de salários como a apanhar, por exemplo, os acessórios, os encargos ditos trabalhistas resultantes do pagamento efetuado. (Voto na íntegra do Relator e Ministro Marco Aurélio no recurso extraordinário no240.785-M G)

Afirmou que o mesmo deve ocorrer com o termo "faturamento", devendo entendêlo em seu sentido técnico, igual o firmado pela jurisprudência e doutrina, como o decorrente de um negócio jurídico, de uma operação, importando, por tal motivo, o que percebido por aquele que a realiza, considerada a venda de mercadoria ou mesmo a prestação de serviços.

Continua sua argumentação, estabelecendo que a base de cálculo da COFINS não pode extravasar o termo faturamento, o valor do negócio, a parcela percebida com a operação mercantil ou similar. Para o relator, o conceito de faturamento representa riqueza própria, quantia que tem ingresso nos cofres de quem procede à venda de mercadorias ou à prestação dos serviços e implica o envolvimento de noções próprias ao que se entende como receita bruta. Afirma que as empresas não faturam ICM e que a conclusão que chegou o Tribunal de origem, a partir de uma premissa errônea, importa na incidência do tributo que é a COFINS, não sobre o faturamento, mas sobre outro tributo já agora da competência de unidade da Federação.

Estabelece que para existir um tributo deve-se ter capacidade contributiva, o que não ocorre com o ICM, que constitui um ônus fiscal ao contribuinte e que 0 valor correspondente ao ICM não tem natureza de faturamento, não servindo de base de cálculo para a COFINS.

A COFINS só pode incidir sobre o faturamento, ou seja, sobre o somatório dos valores das operações negociais realizadas, não se admitindo qualquer valor diverso deste na sua base de cálculo. Afirma que se deve atentar para o princípio da razoabilidade, pressupondo-se que o texto constitucional mostre-se fiel, no emprego de institutos, de expressões e de vocábulos, ao sentido próprio que eles possuem, tendo em vista o que assentado pela doutrina e pela jurisprudência, devendo a lei tributária respeitar 0 estabelecido no artigo 110 do Código Tributário Nacional.

Finaliza sua argumentação que da mesma forma como o Supremo entendeu a expressão "folha de salário" no seu sentido técnico, excluindo os administradores, autônomos e avulsos, por não se conformarem como empregados, não se pode entender 
que a expressão "faturamento" envolve um ônus fiscal, como é o relativo ao ICM, sob pena de desprezar-se o modelo constitucional, adentrando-se a seara imprópria da exigência da contribuição, relativamente a valor que não passa a integrar o patrimônio do alienante quer de mercadoria, quer de serviço, como é o relativo a este imposto. Quem fatura este imposto é o Estado e não o vendedor da mercadoria. Admitir o contrário é querer que a lei ordinária redefina conceitos utilizados por norma constitucional, alterando a Lei Maior e com isso afastando a sua supremacia.

Nesse recurso, a maioria do pleno havia se posicionado pela inconstitucionalidade da inclusão. Contudo, o Supremo ao julgar a Ação Direta de Inconstitucionalidade № 18, acolheu a liminar suscitada pela Advocacia Geral da União (AGU) e suspendeu as ações que buscam a exclusão do ICM da base de cálculo da COFINS no estado que estão. Ou seja, aqueles que conseguiram liminar em suas ações para não pagar essa contribuição com a parcela do imposto sobre operação de circulação de mercadorias continuarão sem pagar, mas aqueles que não conseguiram, continuarão a pagar. 0 STF terá um prazo de 180 dias, a contar da publicação da concessão da liminar para julgar o mérito da ADC. Passado esse prazo, acabará a suspensão dos processos sobrestados.

Ação direta de constitucionalidade-ADC $n=18$

O Presidente da República, representado pelo advogado-geral da União, ajuizou Ação Declaratória de Constitucionalidade (ADC) com o objetivo do Supremo Tribunal Federal declarar a constitucionalidade do artigo 3 , parágrafo $2^{\circ}$, inciso I, da Lei 9.718/98. Essa norma regulamenta a base de cálculo para apuração dos valores da Contribuição para 0 financiamento da seguridade social (COFINS) e dos programas de integração social e de formação do patrimônio do servidor público (PIS/PASEP).

Preliminarmente, 0 autor afirma que há controvérsia juridicamente relevante, pois 0 tema é objeto de controvérsia no âmbito dos Tribunais Regionais Federais (TRF), pois se encontram decisões divergentes a respeito da norma. Muitos julgados, para a advocacia geral da União, concluíram pela validade da norma que inclui o valor do imposto sobre operação de circulação de mercadorias e serviços na base de cálculo da COFINS, entre eles as Súmulas 68 e 94, e o acórdão no Recurso Especial 746038, todos do Superior Tribunal de Justiça (STJ), além de diversos acórdãos dos Tribunais Regionais Federais. 


\section{Exclusão do imposto sobre operações de circulação de mercadorias-ICM da base de cálculo da contribuição para o financiamento social-COFINS}

O advogado-geral argumenta sendo o ICM repassado para "dentro" do "preço de venda", sua importância correspondente deve ser tributada sobre o faturamento ou a receita bruta total das empresas. A ADC ํㅡ 18 sustenta que a norma contida no art. 3ㅇ, § 2으, I, da Lei 9.718/98, ao determinar a inclusão do valor do imposto estadual na base de cálculo da COFINS e do PIS/PASEP, quando não for caso de substituição tributária, está abrangida pelo conceito de faturamento estabelecido pela norma de competência do art. 195, I, da Constituição.

Argumenta ainda que se a decisão do STF determinar, ex tunc com efeito retroativo, a dedução do ICM da base de cálculo da COFINS e do PIS/PASEP produzirá efeitos perversos nas contas públicas da União. As compensações tributárias daí decorrentes "serão astronômicas", em torno de $\mathrm{R} \$ 80$ bi (oitenta bilhões de reais), caso seja levado em conta 0 período dos últimos cinco anos, além de uma receita de $\mathrm{R} \$ 12$ bi (doze bilhões de reais) por ano.

De acordo com a presidência da República, essas são as razões para propor a presente ação para se impedir a ocorrência de uma má compreensão acerca da legitimidade da norma indicada, em face do artigo 195, inciso I, da Constituição, causando grave insegurança jurídica em milhares de relações tributárias além do comprometimento de receitas.

No pedido requereu medida cautelar pleiteando a suspensão dos julgamentos de processos cujas decisões atentem contra a validade da norma em sede liminar e também sobre os efeitos de quaisquer decisões já proferidas no mérito, que tenham afastado a aplicação do artigo 3ำ, parágrafo 1 ํㅡ, inciso I da Lei 9.718/98. Ao final, pede-se a declaração definitiva da constitucionalidade da norma.

Os três argumentos para a propositura dessa ação direta de constitucionalidade são: "preço da mercadoria" abrange o ICM na base de cálculo "por dentro", devendo ser abrangido pelo conceito de faturamento; lesão ao erário público caso seja julgado inconstitucional a inclusão do ICM da base de cálculo da COFINS e insegurança jurídica em milhares de relações jurídicas tributárias, devida à má compreensão do estabelecido no artigo 195, I da Constituição Federal.

Com relação ao primeiro argumento, desmerece maiores discussões, pois nos itens 3 e 4, deixou-se claro que o ICM não compõe o preço da mercadoria, mas o valor da 
operação para fins de cálculo do próprio ICM, e este valor não corresponde ao conceito de faturamento, nem de receita, sendo mero ingresso. Frise-se que não é correto a lei, complementar ou ordinária, restabelecer conceitos já estão definidos e abrangidos pela Constituição Federal.

Com relação ao prejuízo que uma declaração de inconstitucionalidade da inclusão causará ao erário, frise-se que nenhum argumento econômico deve prevalecer diante da Constituição Federal. Esta deve tecer regramentos sobre a economia e não o contrário. Admitir que esta contrarie a Constituição acarretará 0 arruinamento de todo 0 arcabouço constitucional e prejudicará a supremacia constitucional.

É muito fácil invocar esse argumento relacionado à economia para cada violação à lei e à Constituição e admiti-lo válido significa incentivar essa prática do Poder Executivo, que nos últimos anos legisla através de M edida Provisória, majora alíquotas através desta, e desrespeita a Constituição Federal todo ano, especialmente através de Emendas à Constituição.

Argumento tão frágil, não pode ser considerado, ainda mais pelo Supremo, órgão responsável por zelar pela Constituição. Se a Suprema Corte brasileira aceitar argumento tão frágil, será uma grande perda para o Direito pátrio, pois a afronta à Constituição é visível e a União não tem nenhum argumento jurídico forte 0 suficiente para elidir o posicionamento que vinha se formando no Supremo Tribunal, em especial no recurso extraordinário no 240785-M G.

Talvez por não possuir um argumento jurídico contundente é que tenha "apelado" para um de caráter econômico, que reiteradamente é utilizado pela administração federal, com 0 intuito de ver se prevalece suas ambições arrecadatórias desenfreadas, a ponto de violar incessantemente a Constituição.

Com relação à insegurança jurídica, esta não decorre das decisões divergentes nos Tribunais a respeito da constitucionalidade ou não da inclusão do ICM da base de cálculo da COFINS, mas pelo contrário, justamente pelo fato dos Tribunais, especialmente o Superior Tribunal de Justiça, admitir a cobrança de uma contribuição para o financiamento da seguridade social incidindo além dos limites constitucionais, vale dizer, além da base de cálculo estabelecida na Constituição Federal, artigo 195, I. 


\section{Exclusão do imposto sobre operações de circulação de mercadorias-ICM da base de cálculo da contribuição para o financiamento social-COFINS}

Essa ação revela uma tentativa desesperada da União, e especialmente do Presidente, de que não seja declarada inconstitucional a inclusão do imposto sobre operação de circulação de mercadorias da base de cálculo da COFINS, haja vista que no recurso extraordinário "já estava" assegurado o entendimento que tal inclusão é inconstitucional. Foi uma tentativa de atrapalhar o deslinde do referido recurso, impedindo inclusive a declaração da inconstitucionalidade da referida inclusão, e conseqüentemente abrir precedentes.

Segundo 0 informativo no 506 do STF, a questão de ordem suscitada pelo Min. Marco Aurélio no sentido de se prosseguir com o julgamento do RE 240785-MG, e não se iniciar o julgamento da Ação Direta de Constitucionalidade № 18, tendo em conta o disposto no art. 138 do RISTF ("Preferirá aos demais, na sua classe, o processo, em mesa, cujo julgamento tenha sido iniciado."), "[...] o Tribunal, por maioria, considerando que o referido dispositivo regimental faz menção à preferência entre processos de mesma classe, deliberou pela precedência do julgamento da ADC.", em detrimento do recurso extraordinário (STF. Informativo $\mathrm{n}$ 0 506). Nesse ponto, ressaltou o M in. Celso de Mello

\footnotetext{
que o caráter objetivo do processo de fiscalização abstrata imporia e justificaria a precedência do julgamento da ADC em face de um processo de índole meramente subjetiva, sobretudo se considerada a natureza, a extensão e a vinculatividade da decisão que emerge dos processos de controle normativo abstrato.
}

No dia 13 de agosto de 2008, o plenário deferiu a liminar pleiteada pela AGU na $A D C$ no 18 e suspendeu até 0 julgamento do mérito da constitucionalidade da inclusão nessa ação direta, com prazo para julgamento de cento e oitenta dias, os processos que tratam da matéria no estado em que se encontram. Vale dizer, se conseguiram liminar para não pagar o ICM incluso na base de cálculo continuarão não pagando, mas se não conseguiram, continuarão pagando. Foram nove votos favoráveis a suspensão dos processos que versam sobre a inconstitucionalidade, contra dois votos. 0 argumento que prevaleceu para se julgar primeiro a $A D C$ basicamente diz respeito ao efeito erga omnes desta, que terá efeito para todos, não apenas entre as partes (NOTÍCIAS DO STF do dia 13.08.2008). 


\section{Conclusão}

A exclusão do imposto sobre operação de circulação de mercadorias da base de cálculo da contribuição para o financiamento social é um tema de grande relevância no plano jurídico e econômico.

Devido ao fenômeno da repercussão econômica, base de cálculo "por dentro", o ICM incide em sua própria base de cálculo. Como conseqüência, na aquisição da mercadoria, o valor do tributo já se encontra embutido no "preço da mercadoria". Isso ocorre não porque o valor de referido imposto integre o preço da mercadoria, mas por que ele é um tributo indireto, onde o ônus tributário deve ser suportado pelo consumidor e não pelo sujeito passivo que realizou o evento tributário. 0 valor desse imposto compõe na verdade 0 valor da operação dele mesmo, parâmetro jurídico para fins de apuração do seu quantum debeatur, não se admitindo que esse valor integre outro valor da operação que não o do próprio imposto de competência estadual.

O problema, como analisado, é que a União não considera o valor do ICM composto em sua própria base de cálculo como seu valor da operação, mas como o preço da mercadoria. Comete equívoco ao confundir a noção de valor da operação e preço da mercadoria. Para ela, tudo o que ingressa na empresa a título de venda corresponde a faturamento, inclusive a parcela do imposto estadual.

O próprio posicionamento do Superior Tribunal de Justiça comete esse equívoco e considera que o valor do ICM compõe o preço da mercadoria e deve ser entendido como faturamento.

A posição adotada nesse artigo foi pela necessidade da exclusão do ICM da base de cálculo da COFINS, pois esse imposto só incide em sua própria base de cálculo devido ao fenômeno da repercussão econômica, que viabiliza sua característica de ser indireto, repassando o valor do ICM para o consumidor arcar, em vez do empresário. Além do que, essa quantia compõe o valor da operação desse próprio imposto, mas não o preço da mercadoria. É parâmetro jurídico o valor da operação servindo para apuração do próprio imposto estadual. Não é lícito a partir dessa mecânica especial, que só pode produzir eficácia no âmbito estritamente compreendido nos fins da lei tributária, isto é, no plano específico e restrito da base de cálculo do ICM, fazer projeções para outros campos, porque implicaria 


\section{Exclusão do imposto sobre operações de circulação de mercadorias-ICM da base de cálculo da contribuição para o financiamento social-COFINS}

em alargamento do regime nitidamente excepcional, facultando a irradiação dos efeitos deste "anormal" comando em esferas não visadas pelo seu sentido específico.

Na COFINS, só há a previsão do valor da operação jurídica de vendas, de vendas e serviços, ou prestar serviços de qualquer natureza, ou seja, faturamento, ou receita para se cobrar nessa contribuição, mas não há previsão, em nível constitucional ou legal, para que se cobre essa quantia correspondente ao valor do ICM.

Inadmissível também a inclusão, pois a regra-matriz constitucional da COFINS, em sua base de cálculo, não abarca essa quantia correspondente ao imposto estadual, seja no conceito de faturamento, seja no de receita tributável, haja vista que constitui um ônus fiscal para o contribuinte, que deve repassar tal quantia para a Receita Estadual, ou o órgão responsável no Distrito Federal, sendo apenas um ingresso, haja vista que não integra o seu patrimônio, mas receita do Estado ou do Distrito Federal, sendo transitória sua permanência no caixa da empresa.

Pode-se considerar que a inclusão do ICM na base de cálculo da COFINS é inconstitucional, ao não respeitar sua regra-matriz constitucional, haja vista que referido imposto não se amolda ao conceito de faturamento e receita.

O Supremo Tribunal Federal está prestes a se posicionar a respeito do tema, pois tem um prazo de cento e oitenta dias para julgar. Porém, enquanto não julgar, a dúvida e a incerteza se os argumentos jurídicos e constitucionais prevalecerão, ou se as questões políticas e econômicas se sobreporão àqueles permanecerá, sendo de extrema relevância uma atitude desse tribunal com 0 intuito de ver a Constituição Federal e o Sistema Constitucional Tributário respeitado, pois é a Constituição que deverá traçar parâmetros para a Economia e não o contrário.

\section{Referências}

ALVES JR., Luís Carlos Martins. A Inclusão do ICM S na Base de Cálculo do PIS e da COFINS. 0 Cabimento e a Procedência da ADC no 18. Disponível em: «www.fiscosoft.com.br $>$. Acesso em: 10 jun. 2008.

ATALIBA, Geraldo. Hipótese de Incidência Tributária. 6. ed. São Paulo: M alheiros, 2004.

BALEEIRO, Aliomar. Direito Tributário Brasileiro. 9. ed. Rio de Janeiro: RT, 1977. 
CARRAZZA, Roque Antônio. ICM S- Princípio da Não-Cumulatividade- Créditos Relativos a Bens que se destinam a Uso, Consumo ou Ativo Permanente. Direito Tributário. In: MELLO, Celso Antônio Bandeira de (Org.). Estudos em homenagem a Geraldo Ataliba 1. São Paulo: Malheiros, 1997. p. 253-293.

. ICM S. 12. Ed. rev. e amp. até a Emenda Constitucional no 53/2006 e de acordo com a Lei Complementar 87/96 e suas ulteriores modificações. São Paulo: Malheiros, 2007. CARVALHO, Paulo de Barros. Teoria da Norma Tributária. 4. ed. Max Limonad: São Paulo, 2002. 2004.

. Direito Tributário: fundamentos jurídicos da incidência. 3. ed. São Paulo: Saraiva, COÊLHO, Sacha Calmon Navarro. Curso de Direito Tributário Brasileiro. Rio de Janeiro: Forense, 2007.

DENARI, Zelmo. Curso de Direito Tributário. rev. atual. nos termos da Constituição de 1988. São Paulo: Forense, 2000

DERZI, Mizabel. "Notas" ao livro Limitações Constitucionais ao Poder de Tributar, de Aliomar Baleeiro. 7.ed. Rio de Janeiro: Forense, 1997.

FORTES, Fellipe Cianca. A exclusão do ICMS da base de cálculo do IPI. Disponível em: বttp://www.idtl.com.br/artigos/233.html>. Acesso em: 29 maio 2008.

GRECO, M arco Aurélio; ZONARI, Anna Paola. ICM S- M aterialidade e Princípios Constitucionais. In: M ARTINS, Ives Gandra da Silva. Curso de Direito Tributário. Belém: cejup; Centro de extensão Universitária, 1997. p. 143-171. v. 2.

HARADA, Kiyoshi. Exclusão do ICM S da base de cálculo. Disponível em: $<w w w$. fiscosoft.com.br>. Acesso: 28 maio 2008.

INFORM ATIVO DO SITE DIREITO 2. Disponível em: বhttp://www.direito2.com.br/stf/>. Acesso em: 10 jun. 2008.

LARA, Karula Trentin. Redução da Cofins - Exclusão do ICM S da Base de Cálculo para Fins de Cálculo da Contribuição ao Governo Federal. Disponível em: $\varangle$ www.fiscosoft.com.br $>$. Acesso em: 28 maio 2008.

M ACHADO, Hugo de Brito. Curso de Direito Tributário. 26. ed. São Paulo: M alheiros, 2005.

M ELO, José Eduardo Soares de. A Não-Cumulatividade Tributária (ICM S, IPI, ISS, PISE COFINS). 2. ed. São Paulo: Dialética, 2004.

. ICM S: teoria e prática. 7. ed. São Paulo: Dialética, 2004. 


\section{Exclusão do imposto sobre operações de circulação de mercadorias-ICM da base de cálculo da contribuição para o financiamento social-COFINS}

M ILAGRE, Marcos José. Exclusão do ICMS da Base de Cálculo da COFINS e do PIS - Posições Antagônicas do STJ e do STF. Disponível em: $\varangle$ www.fiscosoft.com.br>. Acesso em: 28 maio 2008.

M INATEL, José Antônio. Conteúdo do Conceito de Receita e Regime Jurídico para sua Tributação. MP, 2005.

NEVES, Luis Fernando de Souza. COFINS - Contribuição Social sobre o Faturamento - LC 70/91. Prefácio de Paulo de Barros Carvalho, São Paulo: Max Limond, 1997.

PAULSEN, Leandro. Direito Tributário: Constituição e Código Tributário à luz da doutrina e da jurisprudência. 9. ed. rev. atual. Porto Alegre: Livraria do Advogado: ESM AFE, 2007.

OLIVEIRA, Ricardo M ariz de. Conceito de Receita como Hipótese de Incidência das Contribuições para a Seguridade Social (para efeito da COFINS e da Contribuição ao PIS). Repertório IOB de Jurisprudência, 1/01, 1/15528.

Relatório e Voto na íntegra do Relator e Ministro M arco Aurélio no recurso extraordinário no240.785-M G. Revista Consultor Jurídico. São Paulo. Disponível em: «ttp://conjur.estadao.com.br/static/text/47885,1>. Acesso em: 27 fev. 2008.

SOUZA, Hamilton Dias de. Contribuições Especiais. In: M ARTINS, Ives Gandra da Silva. Curso de Direito Tributário / Coordenador: Ives Gandra da Silva Martins. 8. ed. São Paulo: Saraiva, 2001.

SUPREM 0 Tribunal Federal. Informativo no 506 STF. Disponível em: «www.stf.gov.br>. Acesso em: 10 jun. 2008.

SUPREM O Tribunal Federal. Notícias STF, terça-feira, 11.06.2008. Disponível em: $<w w w . s t f . g o v . b r>$. Acesso em: 11 jun. 2008. 